\title{
Physicochemical Properties of Bosentan and Selected PDE-5 Inhibitors in the Design of Drugs for Rare Diseases
}

\author{
Anna Krupa, ${ }^{1,4}$ Dorota Majda, ${ }^{2}$ Włodzimierz Mozgawa, ${ }^{3}$ Jakub Szlęk, ${ }^{1}$ and Renata Jachowicz ${ }^{1}$
}

Received 14 March 2016; accepted 22 July 2016; published online 5 August 2016

\begin{abstract}
The study provides the physicochemical characteristic of bosentan (BOS) in comparison to tadalafil (TA) and sildenafil citrate (SIL). Despite some reports dealing with thermal characteristic of SIL and TA, physicochemical properties of BOS have not been investigated so far. Recent clinical reports have indicated that the combination of bosentan and PDE-5 inhibitor can improve the effectiveness of pharmacotherapy of pulmonary arterial hypertension $(\mathrm{PAH})$. However, in order to design personalized medicines for therapy of chronic rare diseases, detailed information on the thermal behaviour and solubility of each drug is indispensable. Thus, XRD, DSC and TGA-QMS analyses were applied to compare the properties of the drugs, their thermal stability as well as to identify the products of thermal degradation. The dehydration of BOS started at $70^{\circ} \mathrm{C}$ and was followed by the chemical degradation with the onset at $290^{\circ} \mathrm{C}$. The highest thermal stability was stated for TA, which decomposed at ca. $320^{\circ} \mathrm{C}$, whereas the lowest onset of the thermal decomposition process was stated for SIL, i.e. $190^{\circ} \mathrm{C}$. The products of the drug decomposition were identified. FT-FIR was applied to study intra- and intermolecular interactions between the drug molecules. FT-MIR and Raman spectroscopy were used to examine the chemical structure of the drugs. Chemoinformatic tools were used to predict the polar surface area, $\mathrm{pKa}$, or $\log \mathrm{P}$ of the drugs. Their results were in line with solubility and dissolution studies.
\end{abstract}

KEY WORDS: bosentan; chemoinformatics; combination drugs; dissolution; sildenafil; tadalafil; thermal properties.

\section{INTRODUCTION}

Throughout the last decade, scientists' attention has focused on the development of new drug therapies for patients suffering from rare diseases. According to the European definition of a rare disease, it is a disorder or a disease that affects fewer than 1 person out of 2000 people. In the USA, a disease is rare if it affects fewer than 200,000 Americans at any given time. There are between 6000 and 8000 diseases classified as rare. They concern more than 30 million people in the E.U., among whom $50 \%$ are children. The origin of rare diseases is genetic in $80 \%$ of the cases. It is estimated that other factors, such as viral and bacterial infections, allergies, or environmental toxins, are responsible for $20 \%$ of them.

Nowadays, only about $1 \%$ of drugs used in pharmacotherapy is destined for the treatment of rare diseases. Despite

\footnotetext{
${ }^{1}$ Department of Pharmaceutical Technology and Biopharmaceutics, Faculty of Pharmacy, Medical College, Jagiellonian University, 9 Medyczna str, 30-688, Cracow, Poland.

${ }^{2}$ Department of Chemistry, Jagiellonian University, Cracow, Poland.

${ }^{3}$ AGH - University of Science and Technology, Cracow, Poland.

${ }^{4}$ To whom correspondence should be addressed. (e-mail: a.krupa@uj.edu.pl; akrupa@cm-j.krakow.pl)
}

the fact that advances in modern diagnostic methods facilitate early detection of a rare disease, the development of new drug therapies is slow. The recent forecast analysis, published by EvaluatePharma.com, shows that the number of orphan drugs designed for the therapy of rare diseases should increase by up to $11 \%$ in 2020 .

$\mathrm{PAH}$ is an example of a rare disorder characterized by progressive obliteration of small pulmonary arteries (1). Hypertension of the pulmonary artery can cause right ventricular failure. If $\mathrm{PAH}$ is left untreated, it can lead to death. The origin of PAH may be idiopathic, heritable, or due to lung and left heart diseases. Since the symptoms of PAH occur usually in an advanced form of the disease, the mean survival time after the diagnosis was less than 36 months for many years. The exact cause of PAH is still unknown, but the progress in the understanding of its pathophysiology enabled the development of new therapies based on the treatment of endothelial dysfunction. Although PAH is treatable, the cure for this chronic disease, affecting both children and adults between 20 and 50 years of age, is still not known $(2,3)$.

PAH can be treated by intravenous, subcutaneous, inhaled or oral route, according to medical standards (3). Phosphodiesterase-5 inhibitors (PDE-5i), such as sildenafil citrate (SIL) and tadalafil (TA) as well as endothelin-1 
receptor antagonists, i.e. bosentan (BOS), are approved for the oral pharmacotherapy of $\mathrm{PAH}$ because of their good tolerance (4-6). Apart from urological applications, PDE-5i produce pulmonary vasodilation, inhibiting the breakdown of cyclic guanosine monophosphate (cGMP) in the walls of pulmonary arterioles. Film-coated Revatio ${ }^{\circledR}$ tablets, containing $20 \mathrm{mg}$ of sildenafil citrate, are approved for the treatment of PAH in both children and adults (5). However, there is still lack of dose-adjusted formulations, containing sildenafil citrate for small children. Therefore, in some countries, commercial forms of these drugs, such as Viagra ${ }^{\circledR}$, are used as a source of the active pharmaceutical ingredient (API) for compounding, which may increase the risk of mistakes. Due to the relatively high cost of the drug, there is a problem of counterfeits, increasing the risk of severe side effects.

Recently, film-coated Adcirca ${ }^{\circledR}$ tablets, containing $20 \mathrm{mg}$ of TA, have been approved for a once-daily treatment of PAH in adults. The differences between TA and SIL with regard to pharmacological effects have been widely described $(2,5)$. After oral administration, absorption of TA is the slowest process of all PDE-5i $\left(t_{\max }=2 \mathrm{~h}\right)$, but the pharmacological effect is much longer as compared to SIL, i.e. $36 \mathrm{~h}$ and $2 \mathrm{~h}$ respectively. Nevertheless, slow absorption of TA can be due to its low solubility in water, which may also cause variability in the human drug response. There are also reports, suggesting suitability of TA for the treatment of PAH in children. However, poor solubility in water limits the development of new dosage forms. Thus, microporous silicate carriers, preparing inclusion complexes with modified $\beta$ cyclodextrines or solid dispersions with poloxamer, PEGs and PVP, have been proposed to enhance dissolution of TA (7-10).

In contrast to PDEi, BOS is an orphan drug developed for PAH treatment (6). BOS blocs the binding of endothelin to the receptors, which leads to a decrease in blood pressure. Nowadays, film-coated Tracleer ${ }^{\circledR}$ tablets, containing 62.5 or $125 \mathrm{mg}$ of BOS, are available. The need for the drug dose reduction in pediatrics resulted in the development of a new dosage form, namely dispersible tablets, containing $32 \mathrm{mg}$ of BOS. Multiple studies deal with pharmacokinetics and pharmacodynamics of BOS, but its physicochemical properties have not been analysed in any scientific report so far. It is worth noting that in recent years, there have been several large-scale clinical studies undertaken to evaluate the efficacy of BOS in combination with other PAH-specific drugs, e.g. TA (6). Furthermore, it has been reported that BOS combined with SIL has been found effective in the therapy of Raynaud's phenomenon (11).

The positive results of clinical studies can lead to the development of new combination drugs. Recent advances in 3D printing technology open new vistas to improve patient compliance by manufacturing of polypills. According to this new 'polypill' concept, not only multiple drugs can be enclosed in one tablet, but also their release kinetics can be independent (12). Such a technology seems promising for the development of personalized medicines in the near future (13).

In order to develop individually tailor-made formulations and to optimize their manufacturing process, a detailed characteristic of each drug is needed. However, there is no scientific report, providing the comparison of physical and chemical properties between BOS, SIL and TA, which is necessary for pre-formulation studies of combination drugs to our best knowledge. Therefore, the aim of the present work is to examine thermal properties, crystallinity, morphology and solubility of BOS and selected PDE-5i, such as SIL and TA, which can be helpful in the design of patient-friendly dosage forms, e.g. dispersible forms, buccal films, nanocarriers, or polypills.

To achieve this goal, the following methods are applied in this study: thermal analysis by differential scanning calorimetry (DSC) and thermogravimetric analysis, coupled with quadruple mass spectrometry (TGA-QMS), X-ray powder diffraction (XRD), Raman spectroscopy and FT-IR spectroscopy in mid- and far-infrared range. The shape of the particles is analysed by means of scanning electron microscopy (SEM). The particle size distribution is studied, using the laser diffraction method. Finally, the equilibrium solubility and dissolution of drugs in solvents of three different $\mathrm{pH}$, i.e. $1.2 ; 4.5$ and 7.2 , are also compared.

\section{MATERIALS AND METHODS}

Sildenafil citrate (SIL), tadalafil (TA) and bosentan monohydrate (BOS) in non-micronized form were obtained from Polpharma S.A., Poland. Hydrochloric acid 37\% was obtained from Merck Millipore, Poland. Sodium chloride, potassium dihydrogen phosphate and sodium hydroxide were purchased from Avantor Performance Materials, Poland S.A. All the reagents used were of the analytical grade.

\section{Morphological Analysis}

The morphology of BOS, SIL and TA was analysed, using the scanning electron microscope Hitachi S-4700 (Japan). Powder was adhered to the sample holder by a double-sided copper tape. The surface of powder was coated with carbon using 208 HR carbon sputter coater (Cressington, USA). The images were taken at $\times 50$, and $\times 400$ magnifications.

\section{X-ray Powder Diffraction}

The crystallinity of BOS, TA and SIL was analysed by using Philips X'Pert APD diffractometer. The samples were exposed to $\mathrm{X}$-ray radiation $(\mathrm{Cu}-\mathrm{K} \alpha)$ with the wavelength of $2 \AA$ and a $0.02-\mathrm{mm} \mathrm{Ni}$ filter. The X-ray tube was set up at a voltage of $45 \mathrm{kV}$ and a current of $40 \mathrm{~mA}$. The rate of the scanning was $0.02 \% \mathrm{~min}$ at a range of $2-602 \Theta$.

\section{Thermogravimetric Analysis}

Mettler Toledo TGA/SDTA $851^{\mathrm{e}}$ apparatus calibrated with indium, zinc and aluminum was used. Its accuracy was equal to $10^{-6} \mathrm{~g}$. The samples were placed in an aluminum crucible. Two kinds of measurements were made: the first one in a flow $\left(80 \mathrm{~cm}^{3} \mathrm{~min}^{-1}\right)$ of Ar 5.0 and the second in Air 5.0, at the temperature range from $25^{\circ} \mathrm{C}$ up to $700^{\circ} \mathrm{C}$, at the constant heating rate of $10 \mathrm{~K} \mathrm{~min}^{-1}$.

Additionally, the evolved gaseous products from the decomposition of the compound were identified, using ThermoStar GSD300T Balzers quadruple mass spectrometer 
(QMS). The mass spectrometer was operated in the electron impact mode (EI), using channeltron as a detector. Screening analyses were performed in the selected-ion monitoring (SIM) mode. The following ion characteristics of each molecule, such as $18,30,44$ and 46 for $\mathrm{H}_{2} \mathrm{O}, \mathrm{NO}, \mathrm{N}_{2} \mathrm{O}$ and $\mathrm{NO}_{2}$, respectively, were monitored.

\section{Differential Scanning Calorimetry Analysis}

DSC measurements were carried out using differential scanning calorimetry analysis (DSC) $821^{\mathrm{e}}$ Mettler Toledo apparatus, equipped with intracooler option (Haake). The sample of the studied material was hermetically sealed in an aluminum crucible and measured in the temperature range from 0 to $400^{\circ} \mathrm{C}$, at a heating rate of $5 \mathrm{~K} \mathrm{~min}^{-1}$. The empty pan was used as a reference sample.

\section{Spectroscopic Analysis}

Infrared spectra were measured on Bruker VERTEX $70 \mathrm{v}$ vacuum spectrometer. They were collected in the midand far-infrared region (FT-MIR, FT-FIR), after 256 scans at $2 \mathrm{~cm}^{-1}$ resolution. Samples were prepared, using the standard $\mathrm{KBr}$ (Merck) and polyethylene (Merck) pellet methods for FT-MIR and FT-FIR spectra, respectively.

Raman spectra were collected in the region 1300$100 \mathrm{~cm}^{-1}$ through the confocal Raman microscope, coupled with the single grating LabRAM HR800 spectrometer, equipped with the notch filter and the CCD camera detector. Measurements were performed in backscattering geometry with the 532-nm green line, diode laser (laser power at the sample $\sim 8 \mathrm{~mW}$ ), as excitation, a laser spot size of $\sim 1 \mu \mathrm{m}$ in diameter and a resolution of $<1 \mathrm{~cm}^{-1}$ (grating $1800 \mathrm{~g} / \mathrm{mm})$.

\section{Particle Size Measurement}

The particle size distribution was measured by the laser diffraction method, using the laser diffraction sensor Helos BR (Sympatec GmbH, Germany) and the dry dispersion unit Rodos M (Sympatec GmbH, Germany) with dosing feeder Vibri (Sympatec GmbH, Germany) for dry powder.

\section{Solubility and Dissolution Studies}

The equilibrium solubility of BOS, TA and SIL in solvents of different $\mathrm{pH}$, i.e. $\mathrm{SGF}$ without pepsin of $\mathrm{pH}=$ 1.2, phosphate buffer of $\mathrm{pH}=4.5$ and 7.2 was determined, using the shake-flask method. A surplus of the drug was added to $20 \mathrm{~mL}$ of each solvent. The samples were placed in a water bath (Memmert WNB-14, Germany) and shaken at 37 $\pm 0.5^{\circ} \mathrm{C}$ for $48 \mathrm{~h}$. After centrifugation, the samples were filtered through $0.45 \mu \mathrm{m}$ syringe filter (Millex Millipore, USA) and diluted with the appropriate solvent. The amount of the drug in the samples was determined spectrophotometrically at $\lambda_{\mathrm{TA}}=284 \mathrm{~nm}, \lambda_{\mathrm{SIL}}=290 \mathrm{~nm}, \lambda_{\mathrm{BOS}}=267 \mathrm{~nm}$ (Shimadzu UV-1800, Japan). All the measurements were performed in triplicate.

Mean values and standard deviations (SD) were estimated to quantitatively characterize the distribution of the measured parameters. The one-way ANOVA test was applied to evaluate the differences between the values of solubility related to $\mathrm{pH}$. If the analysis of the variance showed a significant difference between the groups, the Tuckey post hoc test was performed to identify disparate groups. For all the statistical tests used, the significance was assumed if $p$ value was below 0.05 .

The dissolution of TA, SIL and BOS was examined in the automated pharmacopoeial paddle dissolution apparatus, Hanson Research Dissolution Station SR8 Plus with the autosampling device Dissoette II (USA). The dissolution test was performed in $900 \mathrm{~mL}$ of SGF without pepsin, phosphate buffer of $\mathrm{pH}=4.5$ or 7.2 at $37 \pm 0.5^{\circ} \mathrm{C}$. A sample corresponding to $10 \mathrm{mg}$ of TA, $20 \mathrm{mg}$ of SIL, or $62.5 \mathrm{mg}$ of BOS was used for the study, which corresponded to sink conditions in the case of SIL $\left(C / \mathrm{C}_{\mathrm{s}}<0.1\right)$ and non-sink conditions for TA and $\operatorname{BOS}\left(\mathrm{C} / \mathrm{C}_{\mathrm{s}}>0.1\right)$. The paddle rotation speed was set at $50 \mathrm{rpm}$. The samples of $5 \mathrm{~mL}(n=3)$ were withdrawn for $120 \mathrm{~min}$ through the polyethylene filter $(\varnothing=10 \mu \mathrm{m})$ in predetermined time intervals. The amount of the drug dissolved was determined spectrophotometrically as described earlier. The amount of the drug released (\%) over time as well as standard deviation (SD) and relative standard deviation (RSD) were calculated.

The linearity of the dissolution test was evaluated by the linear regression analysis and calculated by the least square regression method. Aliquots of stock solutions, containing $6 \mu \mathrm{g} / \mathrm{mL}$ of SIL, $12.5 \mu \mathrm{g} / \mathrm{mL}$ of TA and $150 \mu \mathrm{g} /$ $\mathrm{mL}$ of BOS respectively were diluted with SGF without pepsin of $\mathrm{pH}=1.2$, phosphate buffer of $\mathrm{pH}=4.5$ or 7.2 to give the concentrations of $6-48 \mu \mathrm{g} / \mathrm{mL}$ for SIL, 1.6$12.2 \mu \mathrm{g} / \mathrm{mL}$ for TA and $3-33 \mu \mathrm{g} / \mathrm{mL}$ for BOS in the range of $\mathrm{pH}$ from 1.2 to 7.2. Each solution was prepared in triplicate.

\section{Computation of Molecular Descriptors}

Molecular descriptors for BOS, SIL base and TA were calculated via chemicalize.org portal, which is a public web resource, developed by ChemAxon (14). The drug solubility in water was obtained from ALOGPS 2.1 web resource of Virtual Computational Chemistry Laboratory (15). In brief, 2D structures of BOS, SIL base and TA were downloaded as separate sdf files from PubChem Database (16). Raw structures were uploaded either into ALOGPS 2.1 Javabased program or Properties Viewer of chemicalize.org. The latter uses the ChemAxon's Marvin package engine; therefore, it is able to optimize geometry and calculate $3 \mathrm{D}$ molecular descriptors.

\section{RESULTS AND DISCUSSION}

\section{Molecular Structure of Drugs}

Chemical structures of BOS, TA and SIL are shown in Fig. 1. BOS is a pyrimidine derivative, containing benzene and sulfonamide group in the structure (Fig. 1). The molecule is achiral. The molecular weight is about $551.6 \mathrm{~g} / \mathrm{mol}$. The chemical structure of PDE-5i, such as SIL and TA, is similar to cyclic guanosine monophosphate (cGMP). Thus, they can act as competitive inhibitors (Fig. 1). TA is a lactam composed of a tryptamine ring. It has molecular weight that 


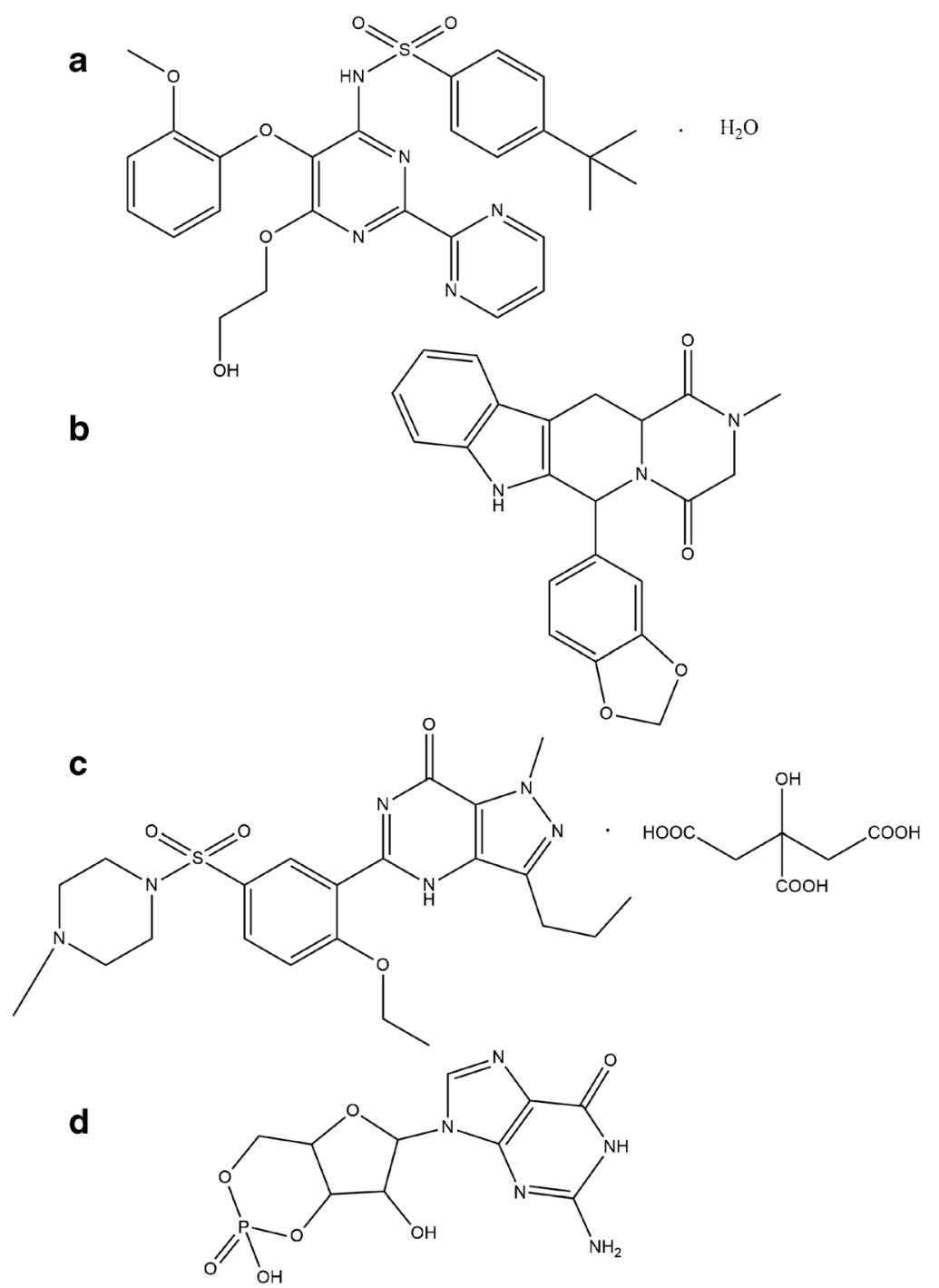

Fig. 1. Chemical structure of bosentan monohydrate (a), tadalafil (b), sildenafil citrate (c) and cyclic guanosine monophosphate (d)

is almost twice as small as SIL, i.e. $389.4 \mathrm{~g} / \mathrm{mol}$. Sildenafil citrate is a derivative of benzenesulphonamides of the molecular weight of ca. $666.7 \mathrm{~g} / \mathrm{mol}$, which contains a pyrimidine ring (Fig. 1).
The comparison of molecular descriptors calculated for BOS, TA and SIL base is shown in Table I. Molecular descriptors calculated for APIs have a wide range of applications. The most investigated one is medicinal

Table I. Comparison of Molecular Properties for Bosentan (BOS), Tadalafil (TA) and Sildenafil (SIL) Base Structures

\begin{tabular}{|c|c|c|c|}
\hline Parameter & BOS & TA & SIL base \\
\hline Mass [Da] & 551.61 & 389.40 & 474.58 \\
\hline Minimal projection area $\left[\AA^{2}\right]$ & 85.93 & 67.01 & 80.19 \\
\hline Maximal projection area $\left[\AA^{2}\right]$ & 125.68 & 96.26 & 118.21 \\
\hline Molecular volume $\left[\AA^{3}\right]$ & 480.97 & 328.28 & 420.99 \\
\hline Polar Surface Area, PSA $\left[\AA^{2}\right]$ & 145.65 & 74.87 & 109.13 \\
\hline Solvent accessible surface area, SASA $\left[\AA^{2}\right]$ & 791.84 & 513.72 & 708.41 \\
\hline $\log \mathrm{P}$ & 4.94 & 1.64 & 1.35 \\
\hline $\log D_{\max }$ & $5.09(\mathrm{pH} \mathrm{2-4)}$ & $1.54(\mathrm{pH} 0-12)$ & $1.56(\mathrm{pH} 7-11)$ \\
\hline $\mathrm{pKa}$ & 5.79 & 15.17 & 5.99 \\
\hline Solubility in water ${ }^{\mathrm{a}}[\mathrm{mg} / \mathrm{mL}]$ & 0.009 & 0.250 & 0.433 \\
\hline
\end{tabular}

${ }^{a}$ Obtained from ALOGPS 
chemistry (17), although recently their potential in representing the molecule characteristics has been applied in the field of toxicology (18) and in pharmaceutical technology during preformulation studies (19) in order to predict solubility (20), melting point (21) and in vitro/vivo correlation (22) among many others.

Molecular properties calculated for BOS, SIL base and TA did not reveal a uniform behaviour; however, general conclusions can be drawn (Table I). SIL base and BOS have the $20-40 \%$ higher molecular mass, projection area (planar) and molecular volume (cubic) than TA. Consequently, the polar surface area (PSA) and solvent accessible surface area (SASA) of both SIL base and BOS are higher as compared to TA. The comparison of $\log \mathrm{P}$ shows differences which reflect drug solubility in water. The higher the value of $\log \mathrm{P}$, the lower the solubility in water is. TA and SIL base with their $\log \mathrm{P}$ values of 1.64 and 1.35 have solubility in water of 0.250 and $0.433 \mathrm{mg} / \mathrm{mL}$, whereas solubility of BOS is only $0.009 \mathrm{mg} / \mathrm{mL}(\log \mathrm{P}, 4.94)$. Values of $\log \mathrm{D}_{\max }$, which correspond to $\log \mathrm{P}$ values, show only slight differences between TA and SIL base, such as 1.54 and 1.56, respectively, in a wide range of $\mathrm{pH}$. Acid dissociation constants indicate that TA with pKa of 15.17 is neutral in physiological fluids. In contrast, SIL base with pKa of 5.99 forms a cation at neutral $\mathrm{pH}$ when one of the nitrogen atoms from piperazine ring is protonated. At $\mathrm{pH}$ of 5.79, neutral and negatively charged sulfonamide groups of BOS are present in the solution.

\section{FT-IR and Raman Spectroscopy}

The application of FT-IR spectroscopy makes it possible to detect counterfeit active compounds or final drug products. With regard to the relatively expensive APIs, such as BOS, TA and SIL, there is a risk that counterfeit drug products can be available on the market. Raman spectroscopy is often used as a tool in process analytical technology (PAT). The main benefit of this technique is the opportunity to monitor the technological process in real time as there is no need for sample preparation prior to spectral analysis. FT-IR and Raman spectroscopy give complementary information on the sample characteristics.

FT-MIR spectra are presented in Fig. 2a. There are eight major absorption peaks in the spectrum of TA, such as $3326 \mathrm{~cm}^{-1}(\mathrm{~N}-\mathrm{H}$ stretching vibration of secondary amine group), $3060 \mathrm{~cm}^{-1}$ (C-H stretching vibrations of aromatic ring), $2904 \mathrm{~cm}^{-1}$ (C-H symmetric stretching vibration of aliphatic $-\mathrm{CH}_{3}$ group $), 1677 \mathrm{~cm}^{-1}(\mathrm{C}=\mathrm{O}$ of amide group), $1646 \mathrm{~cm}^{-1}(\mathrm{C}=\mathrm{C}$ stretching vibrations of aromatic ring), $1436 \mathrm{~cm}^{-1}$ (C-N stretching vibrations), $1041 \mathrm{~cm}^{-1}$ (C-O-C symmetric stretching vibrations) and $745 \mathrm{~cm}^{-1}$ (vibrations from aromatic benzene ring). The differences in FT-IR spectra of sildenafil citrate and sildenafil base have already been described in detail by Melnikow et al. (23). Since both SIL and BOS have $-\mathrm{SO}_{2}$ group in their structures, there are characteristic peaks at 1171 and $1173 \mathrm{~cm}^{-1}$ respectively, corresponding to symmetric stretching vibrations, whereas asymmetric stretching vibrations are visible at $1360 \mathrm{~cm}^{-1}$ for SIL and
$1342 \mathrm{~cm}^{-1}$ for BOS (Fig. 2a). The $3600 \mathrm{~cm}^{-1}$ band can be attributed to less strongly hydrogen-bonded interlayer water molecules in BOS. There is also a wide peak between 3400 and $3200 \mathrm{~cm}^{-1}$, which corresponds to stretching vibrations of $\mathrm{O}-\mathrm{H}$ group in the spectrum of BOS. This peak is not visible in Raman spectrum. There is also a peak at $1053 \mathrm{~cm}^{-1}$ in the FT-MIR spectrum of BOS, indicating that it is a primary alcohol group. Peaks at 1252 and $1019 \mathrm{~cm}^{-1}$ come from aromatic ether, as well as aromatic-aliphatic ether groups of BOS (Fig. 2a). Pyrimidine rings of BOS show characteristic peaks at 1600, 1565, 1504 and $1441 \mathrm{~cm}^{-1}$ in FT-MIR spectra. The first two peaks are also of high intensity in Raman spectrum while the intensity of the others decreases. Furthermore, there is a high intensity peak at $1440 \mathrm{~cm}^{-1}$ in Raman spectrum of BOS, which represents symmetric stretching vibrations of $-\mathrm{CH}_{3}$ group. The intensity of this peak in FT-MIR spectrum is low.

FT-FIR has been found suitable for the analysis of molecular rotations, as well as intermolecular interactions, which can have an impact on the physiological function of bioactive compounds, e.g. amino acids, peptides or proteins (24-26). FT-IR spectra of BOS, TA and SIL determined in a far-infrared range are shown in Fig. $2 \mathrm{~b}$. The intensity of peaks in FT-FIR spectra of SIL and TA is higher than BOS. Weyna et al. (27) showed that TA molecules form supramolecular chains due to the hydrogen bonds between the indole group of one TA molecule and the carbonyl group from the lactam chain of a neighbouring molecule. Similarly to TA, intra- and intermolecular interactions have also been reported for SIL (28). They are due to electrostatic interactions $\mathrm{C}-\mathrm{H} \cdots \mathrm{O}$, as well as hydrogen bonds $\mathrm{N}-\mathrm{H} \cdots \mathrm{O}$.

Monohydrate of BOS forms $\mathrm{O}-\mathrm{H} \cdots \mathrm{O}, \mathrm{O}-\mathrm{H} \cdots \mathrm{N}, \mathrm{N}-$ $\mathrm{H} \cdots \mathrm{O}$ hydrogen bonds with a water molecule and $\mathrm{O}-$ $\mathrm{H} \cdots \mathrm{N}$ intermolecular interactions between the hydroxyl group and pirymidine rings, which results in twodimensional supramolecular structure (29). The presence of hydrogen bonds can be related to the intensive peaks below $200 \mathrm{~cm}^{-1}$ in FT-FIR spectra. In this region, backbone deformations, vibrations of the end $\mathrm{COO}^{-}$or $\mathrm{NH}_{3}{ }^{+}$were found in amino acids. The increasing absorbance with the increasing frequency is visible in the FT-FIR spectrum of BOS (Fig. 2b). It can be related to the size of particles and their tendency to form agglomerates (Fig. 3), which can be high enough for Mie scattering $(30,31)$. The increasing absorbance with the increasing terahertz frequency was described for lactose of various particle sizes as well as for amorphous indomethacin. Mie scattering was induced, especially if the particle size was close to the radiation wavelength. In consequence, the absorbance of the sample increased with wavenumber. In the present study, FT-FIR analysis was carried out in the wavelength range from $450 \mathrm{~cm}^{-1}(22.2 \mu \mathrm{m})$ to $30 \mathrm{~cm}^{-1}$ $(333.3 \mu \mathrm{m})$. SEM pictures shown in Fig. 3 indicate that primary particles of BOS have a tendency to form aggregates and agglomerates. The particle size distribution of BOS presented in Fig. 4 confirms that the particle size of either primary particles or agglomerates is exactly in the range of FT-FIR spectra, which is in line with the conclusions drawn for lactose and indomethacin by Strachan et al. (31). 

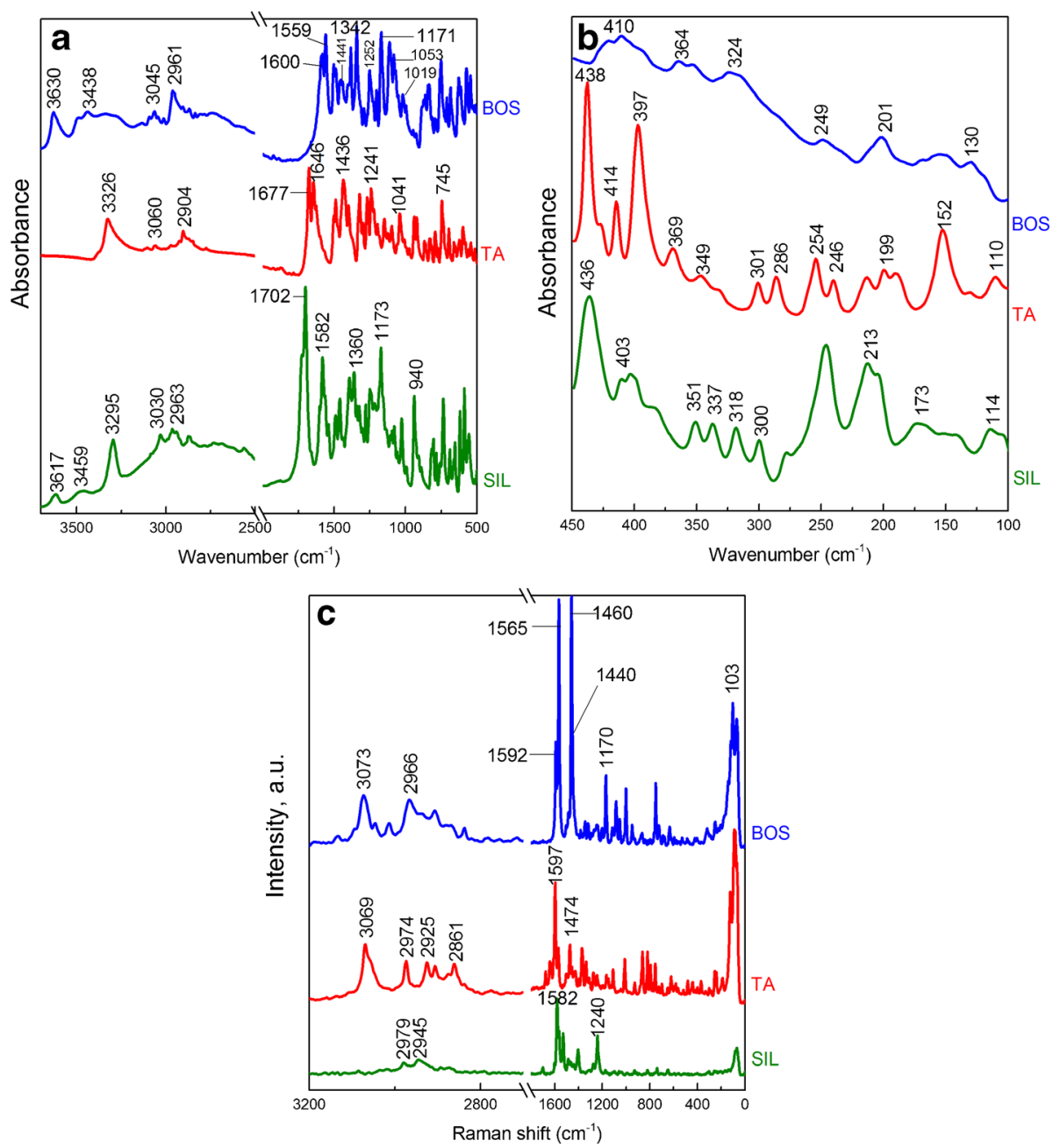

Fig. 2. FT-IR spectra recorded in mid-infrared range (a), FT-IR spectra recorded in far-infrared range (b), Raman spectra (c). Bosentan monohydrate (BOS), tadalafil (TA) and sildenafil citrate (SIL)

\section{Morphology of Drug Particles}

Bosentan (BOS), tadalafil (TA) and sildenafil citrate (SIL) are white crystalline powder. Figure 3 shows that the particles of BOS are irregular, whereas those of TA are rodshaped and sharp-ended. Similarly to TA, the particles of SIL are also rod-shaped. The presence of big agglomerates formed by rod-shaped and plate-shaped particles is visible in SEM pictures of BOS (Fig. 3).

The curves of particle size distribution determined by the laser diffraction method show that the particles of BOS are greater than SIL or TA (Fig. 4). The mean particle size of BOS is almost 15 times as high as SIL, and more than eightfold higher than TA (Table II). However, it cannot be neglected that among particle size distribution curves shown in Fig. 4, only the distribution curve of TA was narrow. In contrast to TA, both SIL and BOS had wide particle size distribution, which may be related to strong powder agglomeration visible in SEM pictures (Fig. 3). Figure 3e, $\mathrm{f}$ also shows that the size of agglomerates ranges from 100 to $400 \mu \mathrm{m}$. They are composed of the primary particles, whose size varies from
20 to $100 \mu \mathrm{m}$. Taking into account that the assessment of the particle size by laser diffraction method relays on the assumption that particles could be represented by an equivalent circle or sphere, the mean particle size of BOS may be overstated.

The diffractograms of BOS, TA and SIL are presented in Fig. 5. They confirm crystalline structure of all the APIs examined. The intensity of peaks in case of TA is the highest of all the examined drugs, which may indicate a highly organized crystalline structure. The intensity of peaks in the diffractograms of SIL and BOS is lower.

There are at least eight crystalline forms of TA (32,33). The position of 2-theta diffraction peaks depends on the kind of the solvent used during the synthesis (Table III). Figure 5 indicates that TA analysed in the present study conforms to form I. The influence of the crystallization process on the properties of SIL crystals was studied in details by Sawatdee et al. (36). A survey of the literature data on BOS reveals that about eight crystalline forms of BOS have been described so far (Table III) $(34,35)$. The form studied in the present research is similar to form A2. 

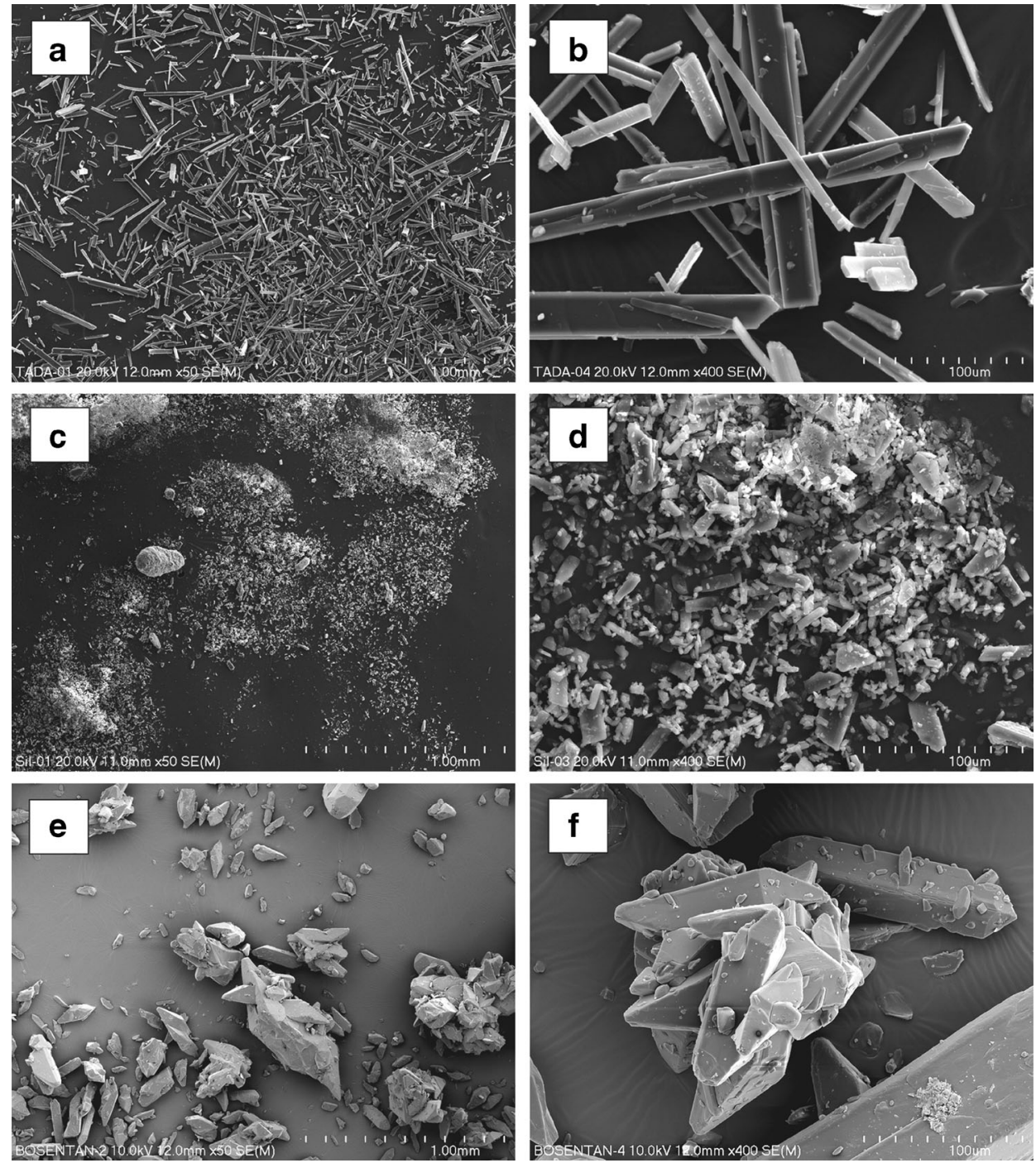

Fig. 3. SEM pictures of TA $(\mathbf{a}, \mathbf{b})$, SIL $(\mathbf{c}, \mathbf{d})$ and BOS $(\mathbf{e}, \mathbf{f})$. Magnification of $\times 50$ on the left and $\times 400$ on the right-hand side

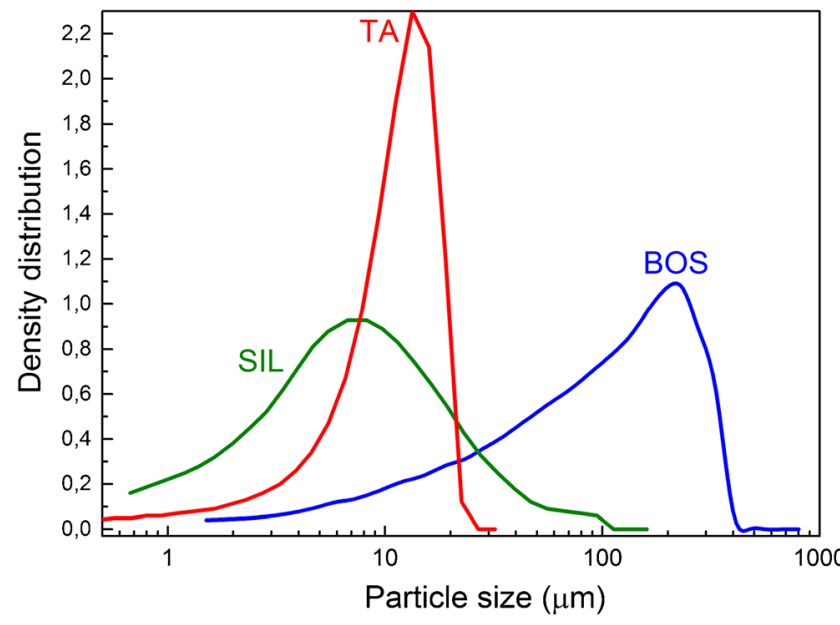

Fig. 4. Particle size distribution of sildenafil citrate (SIL), tadalafil (TA) and bosentan (BOS)

\section{Thermal Properties}

A detailed characteristic of thermal properties of the active pharmaceutical ingredient is needed, especially if hotmelt extrusion (HME) is involved in the manufacturing process of the final dosage form. HME was used to prepare a wide range of drug delivery systems of controlled release properties, pellets, implants, or transdermal patches (37). Recently, special attention has been paid to drug-loaded hotmelt extrudates, which could be used as filaments for the preparation of 3D printed multidrug formulations $(12,38)$.

Table II. Parameters Determined on the Basis of Cumulative Curves of Particles Size Distribution for Bosentan (BOS), Tadalafil (TA) and Sildenafil Citrate (SIL)

\begin{tabular}{lllll}
\hline Drug name & $\mathrm{D}_{10}[\mu \mathrm{m}]$ & $\mathrm{D}_{50}[\mu \mathrm{m}]$ & $\mathrm{D}_{90}[\mu \mathrm{m}]$ & $\mathrm{D}_{99}[\mu \mathrm{m}]$ \\
\hline BOS & 12.44 & 101.77 & 271.28 & 359.84 \\
TA & 3.65 & 11.40 & 17.38 & 20.56 \\
SIL & 1.54 & 6.92 & 23.94 & 72.40 \\
\hline
\end{tabular}




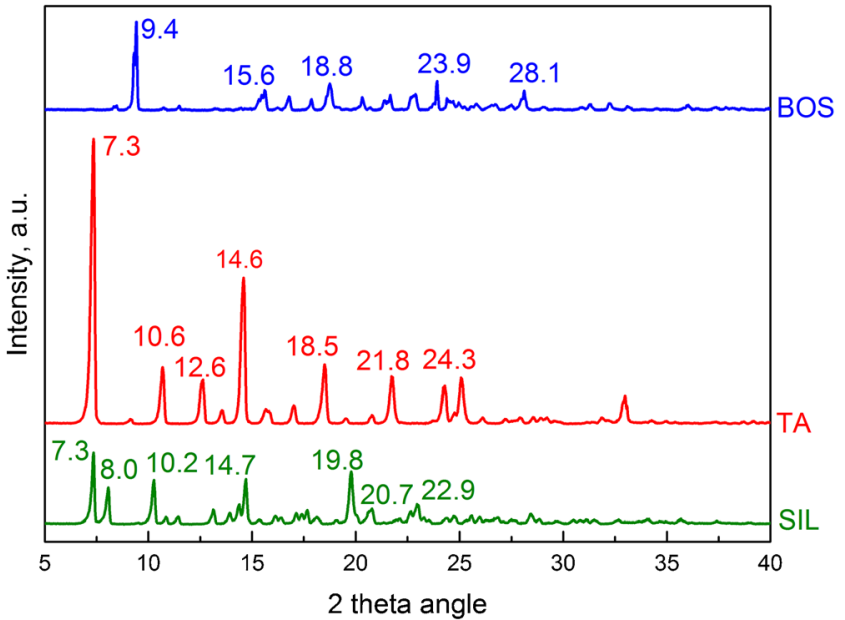

Fig. 5. Diffractograms of bosentan (BOS), sildenafil citrate (SIL) and tadalafil (TA)

Such extrudates were used by Khaled et al. (12) to obtain the combination drug 'polypill', containing five active pharmaceutical ingredients, namely ramipril, pravastatin, atenolol, aspirin and hydrochlorothiazide, which was developed with the aim to make the therapy of hypertension more effective. The aforementioned drugs were distributed in two compartments of the tablet of either immediate or sustained release. Similarly to hypertension, clinical reports, not only on PAH but also on Raynaud's disease, suggest that the combination of PDE-5 inhibitors and BOS can improve the effectiveness of therapy; therefore, the thermal properties of SIL, TA and BOS are investigated in details in the present study $(6,11)$.

Thermal decomposition of sildenafil citrate was already described by Melnikov et al. (23). They observed that the compound decomposes at $189.5^{\circ} \mathrm{C}$, with almost simultaneous melting of the decomposition product. From the comparison of the thermogravimetric and differential thermal analysis curves, it was concluded that, initially, the compound is broken up and later its anionic part is decomposed. Our results stay in agreement with the observation made by Melnikow et al. (23). The first part of thermal decomposition (Fig. 6a), with the onset at $190^{\circ} \mathrm{C}$, originates from the elimination of the citrate ion from the complex. The mass loss $(28 \%)$ matches the calculated value. The decomposition products (line 18 from water and 44 from carbon dioxide) (Fig. 6b) and the sharp endothermic peak with enthalpy 312J/g (Fig. 6c) seem to confirm this statement. The sample heated up to a higher temperature underwent further decomposition with water, carbon dioxides and nitrate oxides evolving (Fig. 6b).

Thermal properties of TA and BOS drugs were not reported in the literature previously; therefore, more attention is paid to them in the current work.

In Fig. 7, the TG/DTG, QMS and DSC results obtained for TA were plotted. To have deeper insight into the products released during decomposition, the thermogravimetric measurements were carried out in air and in argon atmosphere.

It can be seen from Fig. 7a that the gas atmosphere strongly affects the decomposition process. In both studied cases, the first part of decomposition starts at about $320^{\circ} \mathrm{C}$. The evolving products seem to be the same (Fig. 7b, c); however, the mass loss is $50 \%$ in $\mathrm{Ar}$ and $38 \%$ in air atmosphere. The sample heated in the air undergoes further decomposition with maximum speed at $570^{\circ} \mathrm{C}$ and finally burns at over $700^{\circ} \mathrm{C}$ with water, carbon dioxide and nitrate oxides release (Fig. 7b). The drug thermally treated in argon exhibits slight gradual decomposition; however, even at the temperature of $800^{\circ} \mathrm{C}$, more than $40 \%$ of the initial mass is present in the sample (Fig. 7c). The DSC curve (Fig. 7d) manifests the endothermic phase transition with the onset at $299^{\circ} \mathrm{C}$, indicating melting of the drug, as well as the exothermic peak related to the decomposition of the drug, which starts at $350^{\circ} \mathrm{C}$. The enthalpy of melting is $105 \mathrm{~J} / \mathrm{g}$, whereas the enthalpy of exothermic degradation is $160 \mathrm{~J} / \mathrm{g}$.

BOS is used in the therapy in the form of monohydrate. The presence of water in the drug is confirmed by the TG

Table III. Crystalline Forms of TA and BOS forms

\begin{tabular}{|c|c|c|c|}
\hline \multirow[t]{8}{*}{ TA } & I & $7.3^{\circ} 10.6^{\circ} 12.6^{\circ} 14.6^{\circ} 18.5^{\circ} 21.8^{\circ} 24.3^{\circ}$ & \multirow[t]{8}{*}{$(32,33)$} \\
\hline & II & $7.6^{\circ} 14.0^{\circ} 15.2^{\circ} 18.0^{\circ} 22.8^{\circ}$ & \\
\hline & III & $8.3^{\circ} 13.5^{\circ} 17.7^{\circ} 18.4^{\circ}$ & \\
\hline & IV & $7.6^{\circ} 10.6^{\circ} 15.2^{\circ} 18.4^{\circ} 22.7^{\circ}$ & \\
\hline & V & $8.3^{\circ} 15.1^{\circ} 18.8^{\circ} 19.2^{\circ} 20.3^{\circ}$ & \\
\hline & VI & $7.1^{\circ} 9.3^{\circ} 11.4^{\circ} 13.5^{\circ} 17.8^{\circ} 19.2^{\circ} 21.2^{\circ}$ & \\
\hline & VII & $7.0^{\circ} 13.1^{\circ} 17.6^{\circ} 19.0^{\circ} 20.9^{\circ} 24.6^{\circ}$ & \\
\hline & VIII & $7.2^{\circ} 7.6^{\circ} 8.2^{\circ} 13.3^{\circ} 17.6^{\circ} 18.2^{\circ} 22.6^{\circ}$ & \\
\hline \multirow[t]{8}{*}{ BOS } & I & $6.34^{\circ} 10.77^{\circ} 12.69^{\circ} 15.85^{\circ} 19.05^{\circ} 19.84^{\circ} 21.29^{\circ}$ & \multirow[t]{4}{*}{ (34) } \\
\hline & A1 & $9.62^{\circ} 16.34^{\circ} 18.18^{\circ} 22.08^{\circ}$ & \\
\hline & A2 & $8.26^{\circ} 9.15^{\circ} 15.21^{\circ} 15.42^{\circ} 16.63^{\circ} 18.55^{\circ} 30.39^{\circ}$ & \\
\hline & A4 & $4.04^{\circ} 5.62^{\circ} 7.84^{\circ} 17.06^{\circ}$ & \\
\hline & 5 & $4.02^{\circ} 6.12^{\circ} 8.38^{\circ} 9.39^{\circ} 10.04^{\circ} 15.26^{\circ} 17.72^{\circ} 17.98^{\circ} 18.81^{\circ} 19.28^{\circ} 20.31^{\circ} 21.05^{\circ} 27.57^{\circ} 31.91^{\circ}$ & \multirow[t]{4}{*}{$(35)$} \\
\hline & 6 & $3.87^{\circ} 7.51^{\circ} 8.84^{\circ} 11.14^{\circ} 18.74^{\circ} 23.30^{\circ}$ & \\
\hline & 7 & $3.64^{\circ} 4.23^{\circ} 4.95^{\circ} 7.04^{\circ} 7.68^{\circ} 8.23^{\circ} 9.05^{\circ} 9.66^{\circ} 10.48^{\circ} 13.95^{\circ} 15.20^{\circ} 16.17^{\circ} 17.37^{\circ} 18.06^{\circ} 20.03^{\circ} 22.13^{\circ} 26.62^{\circ}$ & \\
\hline & 8 & $\begin{array}{l}9.47^{\circ} 13.41^{\circ} 14.52^{\circ} 15.46^{\circ} 15.73^{\circ} 16.35^{\circ} 16.88^{\circ} 17.99^{\circ} 18.87^{\circ} 19.25^{\circ} 20.53^{\circ} 21.82^{\circ} 23.02^{\circ} 23.83^{\circ} 24.61^{\circ} 24.86^{\circ} \\
25.13^{\circ} 26.03^{\circ}\end{array}$ & \\
\hline
\end{tabular}



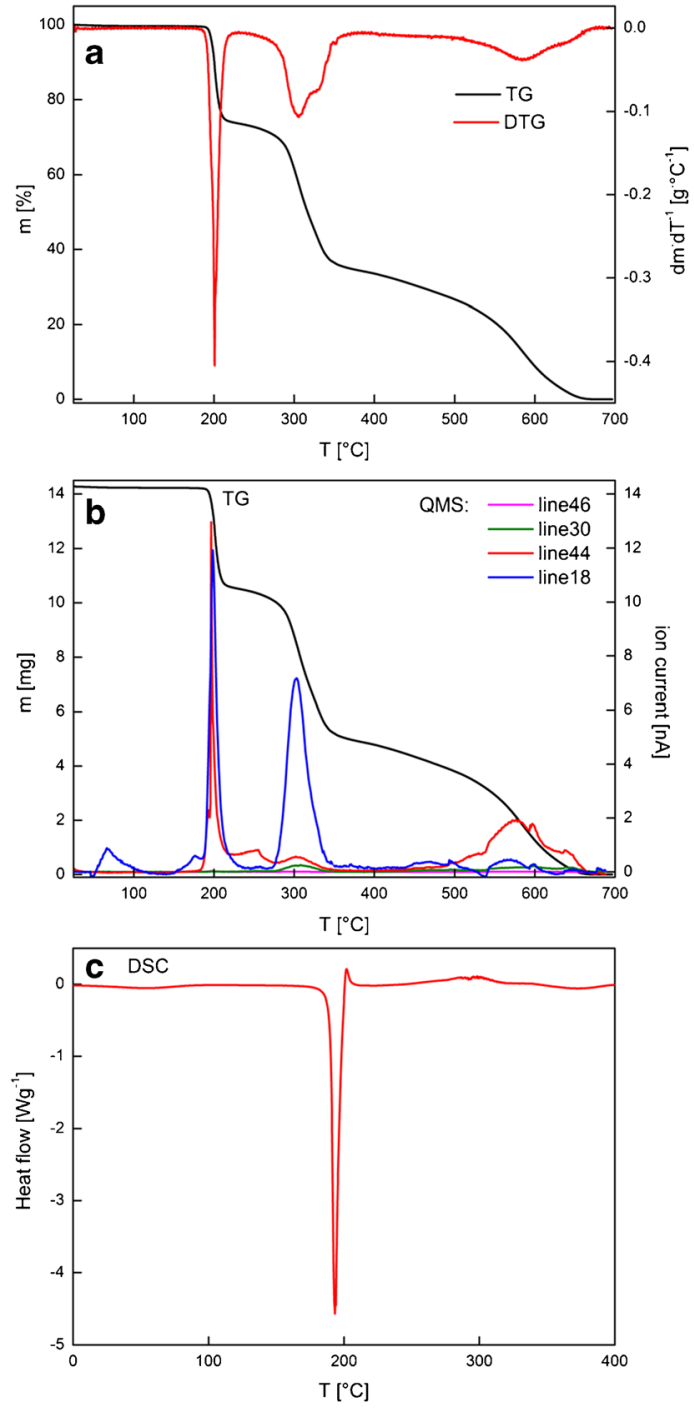

Fig. 6. Thermogravimetric curves of SIL (a) mass spectrometry lines: 18-water, 30-nitric oxide, 44-carbon dioxide, 46-nitrogen dioxide (b) and differential scanning calorimetry plot (c) registered in Air atmosphere at $5 \mathrm{~K} \mathrm{~min}^{-1}$

curve, affirmed by DTG, as well as by spectrometric results, plotted in Fig. 8.

The TG curve of BOS shows a small mass loss just above $70^{\circ} \mathrm{C}$, independently of the atmosphere of the measurement (Fig. 8a), originating from the separation of water from the complex. The second step, with the onset at $290^{\circ} \mathrm{C}$, comes from thermal decomposition of the drug. Gas products evolving during this process were registered by QMS as the line 18, 44, 30 - in air and 16 in Ar atmosphere (Fig. 8b, c). Line 18 illustrates water, 30 -nitrogen oxide (NO) and 16-oxygen. The comparison of the results obtained in air and in Ar suggest that line 44 might come not only from carbon dioxide, but also from tert-butyl group presented in the BOS molecule (mass 45), since the resolution of the mass spectrometer is $1 \mathrm{~m} / \mathrm{z}$. Above $400^{\circ} \mathrm{C}$, the drug undergoes burning in the air atmosphere with carbon dioxide, nitrate oxides and water being released (Fig. 8b). DSC curve (Fig. 8d) shows an endothermic peak associated with water evaporation at about $100^{\circ} \mathrm{C}$, a small endothermic peak at about $195^{\circ} \mathrm{C}$, corresponding to a melting and exothermic peak related to the decomposition of the drug, with maximum at about $300^{\circ} \mathrm{C}$.

The findings presented above lead to the conclusion that TA is the most stable while being heated among all the studied drugs. On the other hand, the temperature at which the process of decomposition starts is the lowest for SIL.

Throughout the development of a combination drug, it is necessary to check if there are any interactions between the active pharmaceutical ingredients, especially if thermal co-processing is planned to be involved in a new technology. Therefore, three binary mixtures composed of the examined drugs in $1+1 \mathrm{wt}$. ratio, as well as one ternary mixture in $1+1+1 \mathrm{wt}$. ratio were prepared. Thermal properties of these formulations were analysed by DSC measurements in order to detect possible interactions between the examined drugs while being heated (Fig. 9).

Figure 9a shows heat flow curves of binary mixture composed of SIL and TA in comparison to pure compounds. DSC curve shows peaks characteristic of pure SIL and TD, such as endotherms of melting and exotherms of decomposition. The endotherm, corresponding to the melting point of SIL, is exactly in the same position as that of the pure drug, whereas the melting endotherm of TD is shifted to lower temperatures. The exothermal decomposition process of the binary formulation starts at lower temperature as compared to pure TD.

Figure $9 \mathrm{~b}$ shows thermal properties of binary mixture, containing BOS and TA in equal amounts. There is only one endotherm characteristic of the melting process of BOS below $200^{\circ} \mathrm{C}$, which is followed by the broad exotherm with the onset at about $280^{\circ} \mathrm{C}$, suggesting the chemical degradation of the mixture.

The heat flow curve of binary mixture prepared of BOS and SIL in $1+1$ wt. ratio is shown in Fig. 9c. The first endotherm is related to the melting point of BOS at about $100^{\circ} \mathrm{C}$. The second corresponds to the melting process of SIL but is broadened with the onset slightly shifted to lower temperatures in comparison to the pure drug. In contrast to pure compounds, there are no exotherms at about $300^{\circ} \mathrm{C}$, which have been replaced by the broad endotherm between 260 and $330^{\circ} \mathrm{C}$.

Thermal properties of the ternary mixture are illustrated in Fig. 9d. There are two endotherms of up to $200^{\circ} \mathrm{C}$, which are characteristic of pure BOS and SIL. The position of the melting endotherm of SIL is also slightly shifted to lower temperatures, as it was described for the binary mixture BOS + SIL shown in Fig. 9c. Then, there is the third endotherm with the onset at about $250^{\circ} \mathrm{C}$, which may correspond either to shifted melting endotherm of pure TD or to the interaction between BOS and SIL, as it was stated previously for their binary mixture.

On the whole, these results provide the evidence that there are no interactions between sildenafil citrate, tadalafil and monohydrate of bosentan either in binary or in ternary mixtures upon being heated together up to $200^{\circ} \mathrm{C}$. Seldom are temperatures higher than $200^{\circ} \mathrm{C}$ used in the pharmaceutical technology due to the jeopardy of 

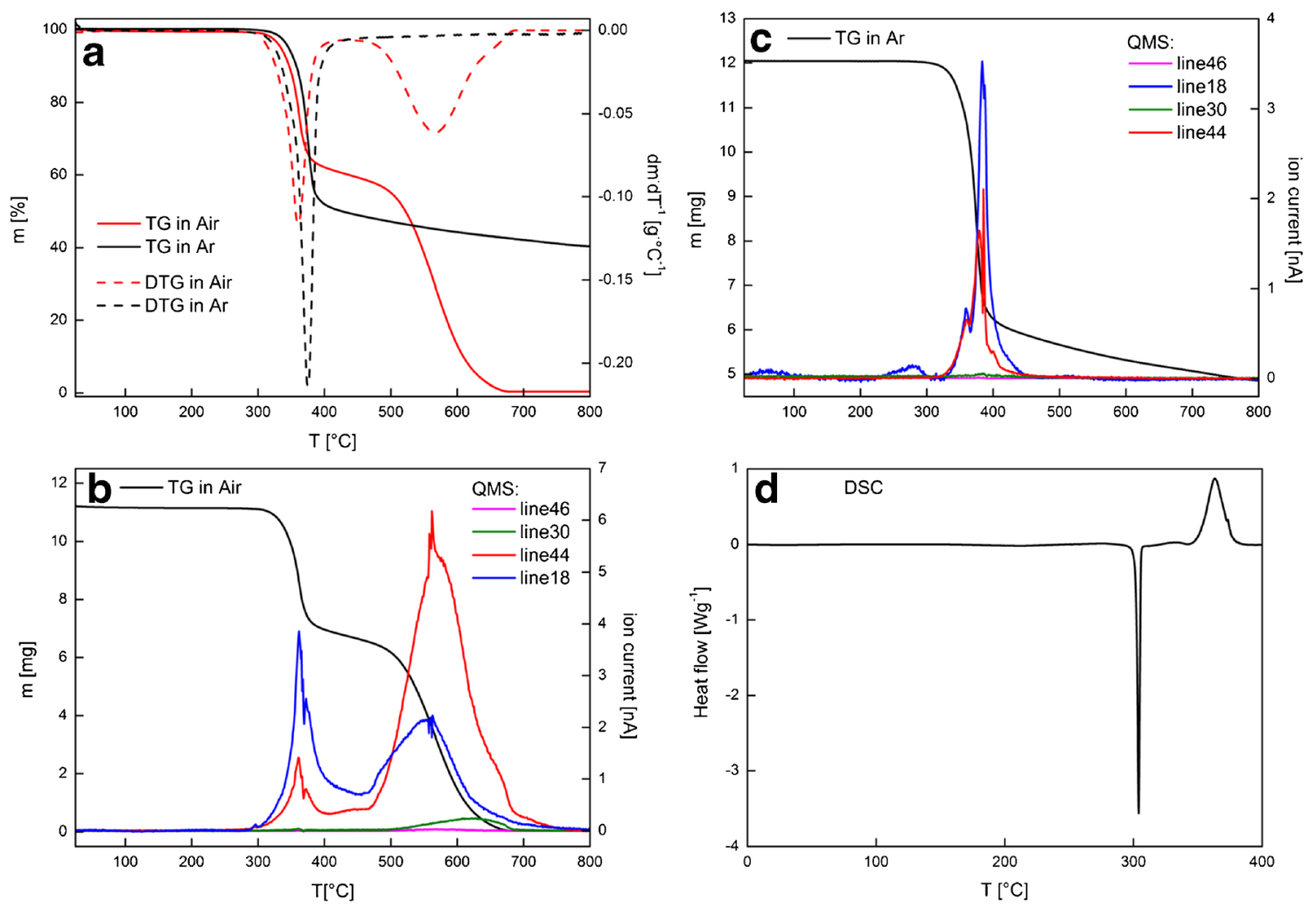

Fig. 7. TG/DTG of TA registered in Air and in Ar atmosphere (a) QMS lines: 18-water, 30-nitric oxide, 44-carbon dioxide, 46-nitrogen dioxide, illustrating the products of drug decomposition in Air (b) and in Ar (c) and DSC curve (d) of the studied sample recorded at $5 \mathrm{~K} \mathrm{~min}^{-1}$
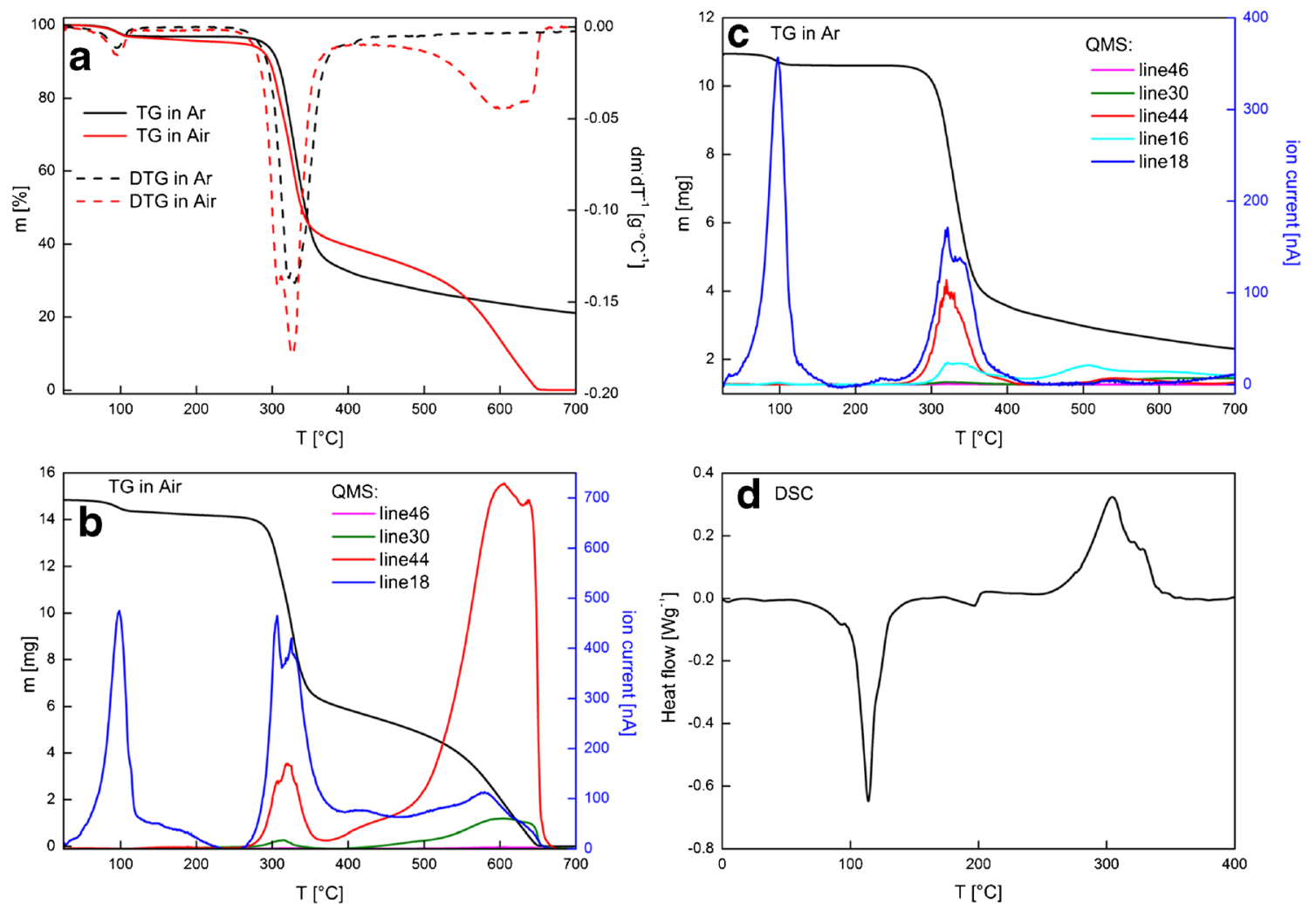

Fig. 8. TG/DTG of BOS registered in Air and in Ar atmosphere (a) QMS lines: 16-oxygen, 18-water, 30-nitric oxide, 44carbon dioxide or tert-butyl group, 46-nitrogen dioxide, illustrating the products of drug decomposition in Air (b) and in Ar (c) and DSC curve (d) of the studied sample recorded at $5 \mathrm{~K} \mathrm{~min}^{-1}$ 

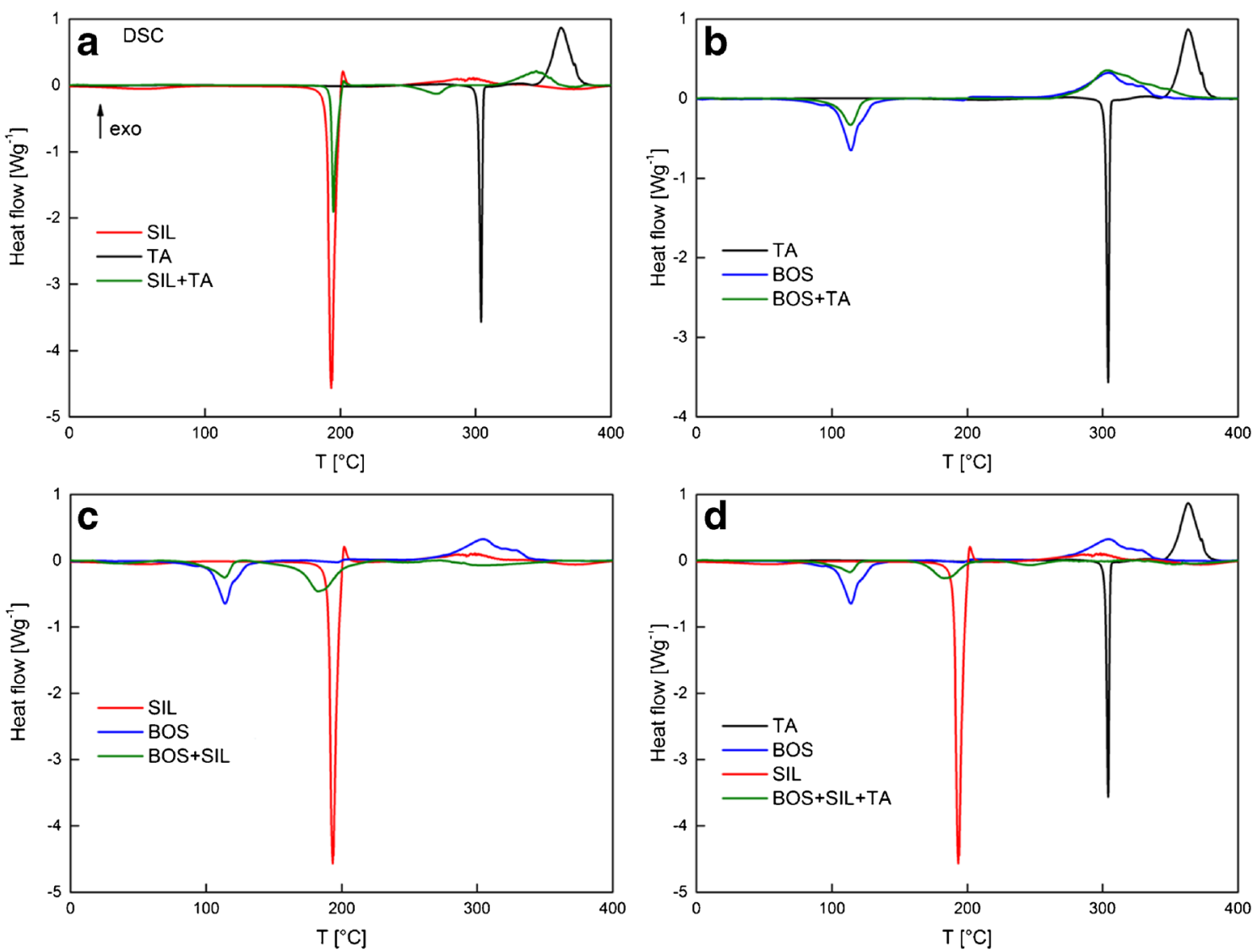

Fig. 9. Heat flow curves of binary mixtures composed of: SIL and TA $1+1$ (a), TA and BOS $1+1$ (b), SIL and BOS $1+1$ (c) and ternary mixture BOS, TA, SIL $1+1+1$ (d) in comparison to pure compounds recorded at $5 \mathrm{~K} \mathrm{~min}^{-1}$

the chemical degradation of thermally sensitive compounds. Thus, the conclusion that there is no risk of interactions between the examined drugs can be drawn.

\section{Solubility and Dissolution Assessment}

BOS and TA are classified as BCS class II drugs because they are insoluble in water and highly permeable compounds. In contrast to TA and BOS, SIL is a highly soluble and highly permeable drug from BCS class I. The results of equilibrium solubility determined for BOS, TA and SIL in solvents of three different $\mathrm{pH}$, such as $1.2 ; 4.5$ and 7.2 , respectively, are presented in Fig. 10. The equilibrium solubility of BOS is significantly higher in $\mathrm{pH}=7.2$ than in $\mathrm{pH}$ of 1.2 or 4.5 $(p<0.05)$. The solubility of TA is slightly higher in $\mathrm{pH}=1.2$, i.e. $4.06 \pm 0.04 \mu \mathrm{g} / \mathrm{mL}$ than in $\mathrm{pH}$ of 4.5 or 7.2 when it is about $3.76 \mu \mathrm{g} / \mathrm{mL}$ (Fig. 10b).

These findings are in accordance with the calculated molecular descriptors. The plateau of $\log \mathrm{D}_{\max }$ observed in the wide range of $\mathrm{pH}$ values (up to 12) indicates that only in highly alkaline solutions, the solubility of TA increases. Moreover, the value of solvent accessible surface area shows that the molecules of TA have less of the space accessible for the solvent than BOS and SIL. In consequence, an increase in the solubility of TA may be difficult to achieve.

The saturation solubility of SIL depended significantly on $\mathrm{pH}$ of the solvent $(p<0.05)$. The highest solubility of
$33.96 \pm 4.16 \mathrm{mg} / \mathrm{mL}$ was in SGF. The higher the $\mathrm{pH}$ of the solvent, the lower the solubility was (Fig. 10c). The equilibrium solubility of SIL in phosphate buffer of $\mathrm{pH}=4.5$ was $7.52 \pm 0.64 \mathrm{mg} / \mathrm{mL}$, whereas in $\mathrm{pH}=7.2$ it deceased to $4.56 \pm$ $0.06 \mathrm{mg} / \mathrm{mL}$. In the case of SIL base, the calculated chemical descriptors, such as $\mathrm{pK}_{\mathrm{a}}, \log \mathrm{P}$ and $\log \mathrm{D}_{\text {max }}$, reflected the general tendency of the molecule to increase its solubility in acidic solutions. Thus, the preferable $\mathrm{pH}$ is below 4, where protonated amine group of piperazine ring is the major species.

The dissolution profiles of TA and SIL are shown in Fig. 11. Similarly to the results of equilibrium solubility, the dissolution of SIL depended also on $\mathrm{pH}$ of the solvent, used for the dissolution study (Fig. 11a). Since sildenafil citrate is a salt formed of the sildenafil weak base and citric acid group, its dissolution in SGF of $\mathrm{pH}=1.2$ is immediate. The entire drug is dissolved after $5 \mathrm{~min}$. The increase in $\mathrm{pH}$ caused a decrease in solubility of SIL; therefore, after $120 \mathrm{~min}$, about $90 \%$ of SIL dissolved in phosphate buffer of $\mathrm{pH}=7.2$ (Fig. 11a).

In contrast to SIL, the dissolution of TA was less dependent on $\mathrm{pH}$ (Fig. 11b). Since TA is poorly soluble in water, the amount of TA dissolved after $120 \mathrm{~min}$ in SGF and phosphate buffer of $\mathrm{pH}=4.5$ was only about $15 \%$. The amount of TA dissolved in the phosphate buffer of $\mathrm{pH}=$ 7.2 was slightly higher, i.e. ca. $25 \%$. However, the particles of TA are very hydrophobic and they remained on the surface of the solvent during all the dissolution study. Thus, 

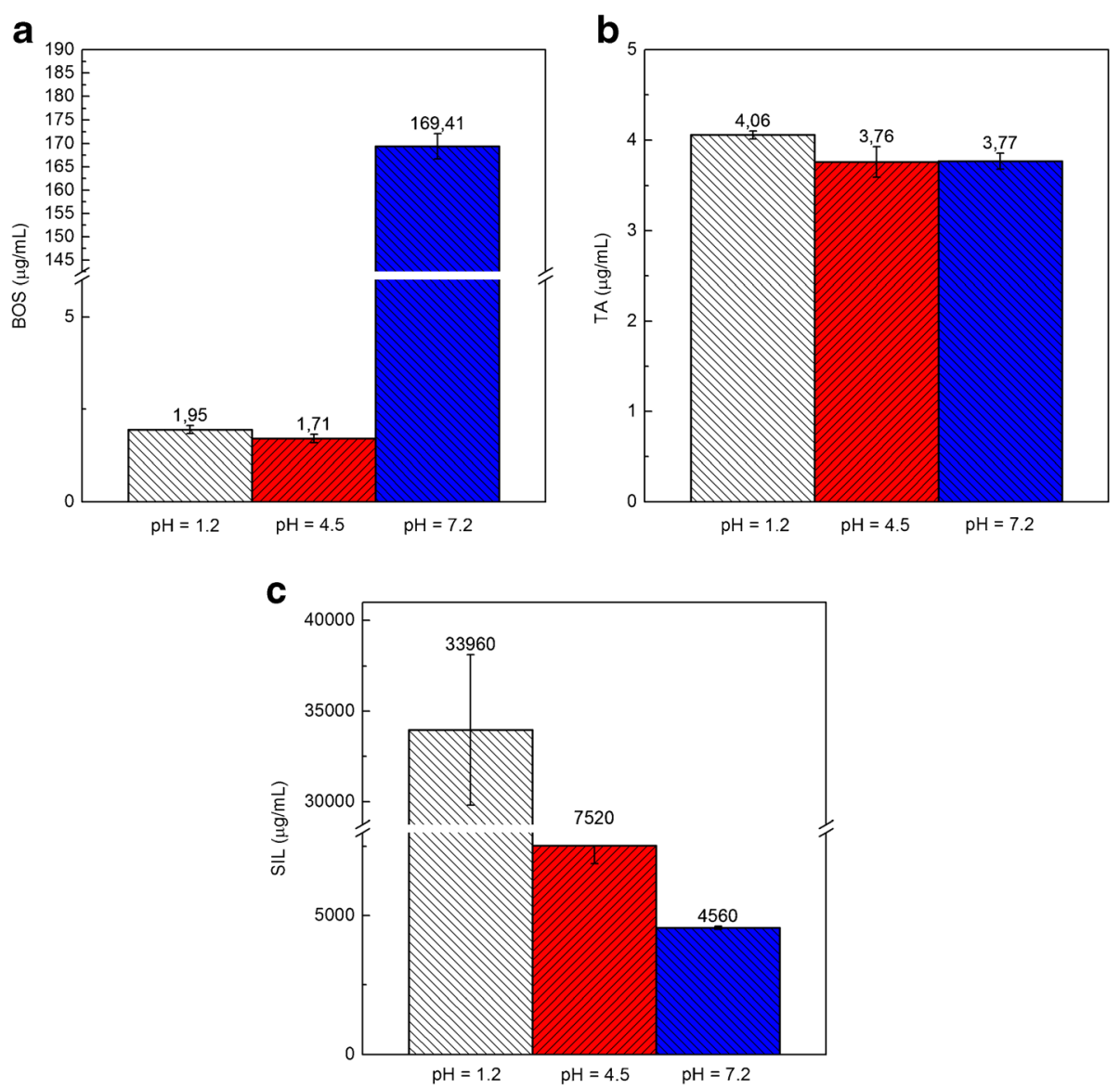

Fig. 10. Equilibrium solubility of BOS (a), TA (b) and SIL (c) in: SGF without pepsin ( $\mathrm{pH}=1.2)$, phosphate buffer of $\mathrm{pH}=4.5$ and phosphate buffer of $\mathrm{pH}=7.2$ determined at $37^{\circ} \mathrm{C}$

the application of a modified SGF by the addition of a surfactant, such as $0.1 \%$ SLS, was investigated. The particles of TA were wetted. There was no floatation of the drug particles during the analysis. The amount of TA dissolved in the modified SGF increased from 15 to $45 \%$ after $120 \mathrm{~min}$ (Fig. 11b).

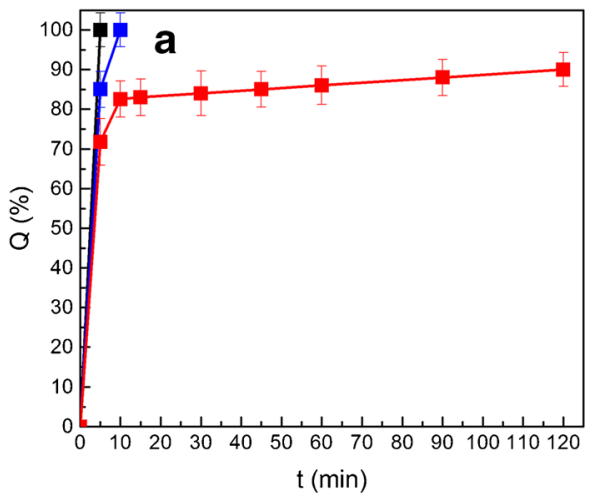

Dissolution studies of BOS showed that regardless of the solvent used, the amount of the drug dissolved after $120 \mathrm{~min}$ was below $5 \%$ (data not shown). In consequence, the application of a wetting agent seems indispensable, and it will be investigated in further studies.

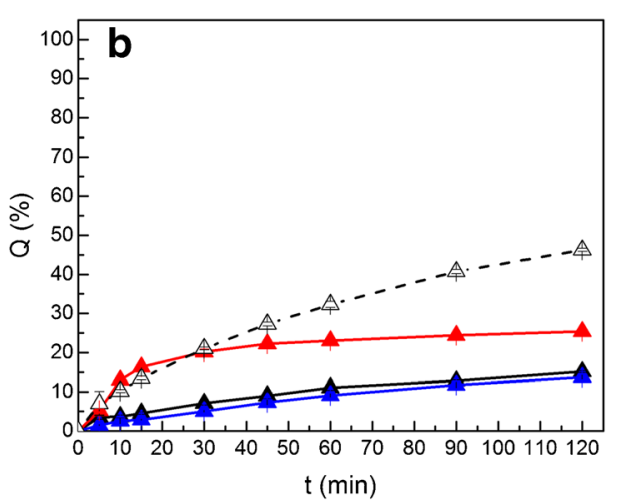

Fig. 11. Dissolution profiles of: SIL (a) and TA (b) in SGF of $p H=1.2$ (black solid line and symbols); phosphate buffer of $p H=4.5$ (blue solid line and symbols) and phosphate buffer of $p H=$ 7.2 (red solid line and symbol); dissolution profile of TA in modified SGF with 0.1\% SLS (black dotted line and open symbols) 
The dissolution test makes it possible to compare new formulation candidates. In the present study, the reliability of the data was determined by the evaluation of precision, measured as intra-assay repeatability by means of RSD, which did not exceeded $5 \%$, demonstrating suitable precision of all the dissolution tests.

The standard curves constructed for SIL, TA and BOS by plotting average absorbance vs. the drug concentration show good linearity in all the studied solvents in the following ranges: $6.0-48.0 \mu \mathrm{g} / \mathrm{mL}\left(r^{2}=0.9939-0.9994\right), 1.6-12.2 \mu \mathrm{g} / \mathrm{mL}$ $\left(r^{2}=0.983-0.991\right), 3.0-33.0 \mu \mathrm{g} / \mathrm{mL} \quad\left(r^{2}=0.9982-0.9996\right)$ for SIL, TA and BOS respectively. The RSD for each point was less than $2 \%$. These results indicate that the method was linear for all the examined drugs, within the specification limits.

\section{CONCLUSIONS}

The present study shows detailed characteristics of the thermal stability of BOS, TA and SIL, which can be helpful in the development of new combination medicines for the treatment of PAH. It was shown that TA has the highest melting point, ca. $300^{\circ} \mathrm{C}$, and the highest stability upon being heated among all the studied drugs. In contrast, the temperature at which the process of decomposition starts is the lowest for SIL (the onset at $190^{\circ} \mathrm{C}$ ). Similarly to TA, the melting point of BOS is also high $\left(\mathrm{Tm}=195^{\circ} \mathrm{C}\right)$. Since BOS is a monohydrate, attention should be paid to the dehydration process which starts at $70^{\circ} \mathrm{C}$. The products of thermal decomposition of all the examined drugs in Air and Ar have been identified.

Chemoinformatic tools, such as the ChemAxon's Marvin package engine, have been applied to determine $\mathrm{pKa}, \log \mathrm{P}$ and the polar surface area, on the basis of the drug chemical structure. The results of morphological analysis by SEM and laser diffraction method revealed that the examined drugs differ in the mean particle size and in particle shape. The particle size increased in the following order: SIL $<$ TA $<$ BOS. Furthermore, it was shown that BOS has a high tendency to form agglomerates, which may be the reason for high values of the mean particle size. The presence of agglomerated BOS particles could also be responsible for Mie scattering, which results in the increasing absorbance with the increasing frequency in the FT-FIR spectrum of BOS. Molecular rotations, as well as intermolecular interactions due to the formation of hydrogen bonds, have been confirmed by high intensity peaks visible in the FT-FIR spectra of SIL and TA.

The solubility and dissolution studies of SIL and BOS depend on $\mathrm{pH}$, whereas the solubility and dissolution of TA were similar regardless of $\mathrm{pH}$ of the solvent. Since SIL is a salt formed of a weak organic base (sildenafil) and citrate anion, the solubility of SIL, especially in acidic $\mathrm{pH}$, is the highest of all the examined APIs. The solubility of BOS in alkaline $\mathrm{pH}$ was more than 40 times higher than TA, whereas in acid $\mathrm{pH}$, the solubility of BOS was twice as small as the solubility of TA. The results of dissolution studies showed that, after $15 \mathrm{~min}$, more than $80 \%$ of SIL was dissolved in all the tested solvents. However, the dissolution of SIL in $\mathrm{pH}$ of 7.2 was slower than in $\mathrm{pH}$ of 1.2 or 4.5 , indicating that $\mathrm{pH}$ of the solvent had only little influence on the dissolution of TA. Nonetheless, the application of a surfactant to the dissolution medium seems indispensable for an accurate analysis of the dissolution of TA and BOS.

\section{ACKNOWLEDGMENTS}

The authors wish to express their gratitude to Marek Kula from ATEST Company in Kielce for the particle size analysis. ATEST Company is an exclusive sales representative of SympaTEC GmbH, Germany in Poland.

The research was performed thanks to the SONATA no DEC-2012/07/D/NZ7/01673 grant, funded by the National Centre of Science in Poland.

Open Access This article is distributed under the terms of the Creative Commons Attribution 4.0 International License (http://creativecommons.org/licenses/by/4.0/), which permits unrestricted use, distribution, and reproduction in any medium, provided you give appropriate credit to the original author(s) and the source, provide a link to the Creative Commons license, and indicate if changes were made.

\section{REFERENCES}

1. Montani D, Chaumais MC, Guignabert C, Günther S, Girerd B, Jaïs $\mathrm{X}$, et al. Targeted therapies in pulmonary arterial hypertension. Pharmacol Therapeut. 2014;141:172-91.

2. Olsson KM, Hoeper MM. Novel approaches to the pharmacotherapy of pulmonary arterial hypertension. Drug Discov Today. 2009;14:284-90.

3. Vaidya B, Gupta V. Novel therapeutic approaches for pulmonary arterial hypertension: unique molecular targets to site-specific drug delivery. J Control Rel. 2015;211:118-33.

4. Frey MK, Lang I. Tadalafil for the treatment of pulmonary arterial hypertension. Expert Opin Pharmacother. 2012;13:747-55.

5. Magee AG, Makhecha S, Bentley S. Risk-benefit considerations when prescribing phosphodiesterase-5 inhibitors in children. Expert Opin Drug Saf. 2015;14:633-42.

6. Mathier MA, Ishizawar D. Bosentan. Expert Opin Pharmacother. 2010;11:1023-34.

7. Badr-Eldin SM, Elkheshen SA, Ghorab MM. Inclusion complexes of tadalafil with natural and chemically modified $\beta$ cyclodextrins I. Preparation and in-vitro evaluation. Eur J Pharm Biopharm. 2008;70:819-27.

8. Kumar R, Sevukarajan M, Vulava J, Pavankumar AG, Deepthi Y, Manjunath M, et al. Improvement of dissolution characteristics and bioavailability of tadalafil by solid dispersion technique using water-soluble polymers. Int $\mathrm{J}$ Adv Pharm. 2012;2:56-63.

9. Mehanna MM, Motawaa AM, Samaha MW. Tadalafil inclusion in microporous silica as effective dissolution enhancer: optimization of loading procedure and molecular state characterization. J Pharm Sci. 2011;100:1805-18.

10. Vyas V, Sancheti P, Karekar P, Shah M, Pore Y. Physicochemical characterization of solid dispersion systems of tadalafil with poloxamer 407. Acta Pharm. 2009;59:453-61.

11. Bellando-Randone S, Lepri G, Bruni C, Blagojevic J, Radicati A, Cometi L, et al. Combination therapy with bosentan and 
sildenafil improves Raynaud's phenomenon and fosters the recovery of microvascular involvement in systemic sclerosis. Clin Rheumatol. 2016;35:127-32.

12. Khaled S, Burley JC, Alexander MR, Yang J, Roberts CJ. 3D printing of five-in-one dose combination polypill with defined immediate and sustained release profiles. J Control Rel. 2015;217:308-14.

13. Park K. 3D printing of 5-drug polypill. J Control Rel. 2015;217:352

14. Swain M. Chemicalize.org. J Chem Inf Model. 2012;52:613-5.

15. Tetko IV, Tanchuk VY, Kasheva TN, Villa AE. Estimation of aqueous solubility of chemical compounds using E-state indices. J Chem Inf Comp Sci. 2001;41:1488-93.

16. Kim S, Thiessen PA, Bolton EE, Chen J, Fu G, Gindulyte A, et al. PubChem substance and compound databases. Nucleic Acids Res. 2016;4:D1202-13.

17. Rybka M, Mercader AG, Castro EA. Predictive QSAR study of chalcone derivatives cytotoxicity activity against HT-29 human colon adenocarcinoma cell lines. Chemometr Intell Lab. 2014;132:18-29.

18. Polak S, Wiśniowska B, Glinka A, Fijorek K, Mendyk A. Slow delayed rectifying potassium current (IKs)-analysis of the in vitro inhibition data and predictive model development. J Appl Toxicol. 2013;33:723-39.

19. Szlęk J, Pacławski A, Lau R, Jachowicz R, Mendyk A. Heuristic modeling of macromolecule release from PLGA microspheres. Int J Nanomed. 2013;8:4601-11.

20. Xiao F, Gulliver JS, Simcik MF. Predicting aqueous solubility of environmentally relevant compounds from molecular features: a simple but highly effective four-dimensional model based on project to latent structures. Water Res. 2013;47:5362-70.

21. Nigsch F, Bender A, Van Buuren B, Tissen J, Nigsch E, Mitchell JBO. Melting point prediction employing k-nearest neighbor algorithms and genetic parameter optimization. J Chem Inf Model. 2006;46:2412-22.

22. Mendyk A, Tuszyński PK, Polak S, Jachowicz R. Generalized in vitro-in vivo relationship (IVIVR) model based on artificial neural networks. J Drug Des Devel Ther. 2013;7:223-32.

23. Melnikov P, Corbi PP, Cuin A, Cavicchioli M, Guimaaes WR. Physicochemical properties of sildenafil citrate (Viagra) and sildenafil base. J Pharm Sci. 2003;92:2140-3.

24. Gaillard T, Trivella A, Stote RH, Hellwig P. Far infrared spectra of solid state L-serine, L-threonine, L-cysteine, and L- methionine in different protonation states. Spectrochim Acta A Mol Biomol Spectrosc. 2015;150:301-7.

25. Mantsch HH, Naumann D. Terahertz spectroscopy: the renaissance of far infrared spectroscopy. J Mol Struct. 2010;964:1-4.

26. Matei A, Drichko N, Gompf B, Dressel M. Far-infrared spectra of amino acids. Chem Phys. 2005;316:61-71.

27. Weyna DR, Cheney ML, Shan N, Mazen MH, Wojtas $€$, Zaworotko MJ. Crystal engineering of multiple-component organic solids: pharmaceutical cocrystals of tadalafil with persistent hydrogen bonding motifs. Cryst Eng Comm. 2012;14:237780.

28. Yathirajan HS, Nagaraj B, Nagaraja P, Bolte M. Sildenafil citrate monohydrate. Acta Crystallogr. 2005;E61:489-91.

29. Kaur M, Jasinski JP, Keeley AC, Yathirajan HS, Betz R, Gerber T, et al. Bosentan monohydrate. Acta Crystallogr. 2013;E69:o123 .

30. Strachan CJ, Howell SL, Rades T, Gordon KC. A theoretical and spectroscopic study of carbamazepine polymorphs. J Raman Spectrosc. 2004;35:401-8.

31. Strachan CJ, Rades T, Newnham DA, Gordon KC, Pepper M, Taday PF. Using terahertz pulsed spectroscopy to study crystallinity of pharmaceutical materials. Chem Phys Lett. 2004;390:204.

32. Wizel S, Krochmal B, Givant A, Diller D. Tadalafil crystal forms and processes for preparing them. US 2006/0111571 A1.

33. Miclaus MO, Kacso IE, Martin FA, David L, Pop MM, Filip C, et al. Crystal structure and desolvatation behavior of the tadalafil monosolvates with acetone and methyl ethyl ketone. J Pharm Sci. 2015;104:3782-8.

34. Dixit G, Gaikwad N, Naindu PH, Pradhan NS, Valgeirsson J. Novel polymorphs of bosentan. US 2011/0014291 A1.

35. Gaitonde A, Manojkumar B, Mekde S, Bansode P, Shinde D, Phadtare S. Crystalline forms of bosentan. US Patent 8.530.488 B2; 2013.

36. Sawatdee S, Pakawatchai C, Nitichai K, Srichana T, Phetmung $\mathrm{H}$. Why sildenafil and sildenafil citrate monohydrate crystals are not stable? Saudi Pharm J. 2015;23:504-14.

37. Breitenbach J. Melt extrusion: from process to drug delivery technology. Eur J Pharm Biopharm. 2002;54:107-17.

38. Goyanes A, Wang J, Buanz A, Martinez-Pacheco R, Telford R, Gaisford S, et al. 3D Printing of medicines: engineering novel oral devices with unique design and drug release characteristics. Mol Pharmaceutic. 2015;12:4077-84. 